\title{
The Impact of Sharing Economy on China's Labor Relations in the Internet Era
}

\author{
Siyu Chen \\ School of Business Adiministration, South China University of Technology, Guangzhou, China \\ Email: bigfish_chen@163.com
}

How to cite this paper: Chen, S.Y. (2019) The Impact of Sharing Economy on China's Labor Relations in the Internet Era. Journal of Human Resource and Sustainability Studies, 7, 149-159. https://doi.org/10.4236/jhrss.2019.72011

Received: March 17, 2019

Accepted: April 9, 2019

Published: April 12, 2019

Copyright $\odot 2019$ by author(s) and Scientific Research Publishing Inc. This work is licensed under the Creative Commons Attribution International License (CC BY 4.0).

http://creativecommons.org/licenses/by/4.0/

\begin{abstract}
In recent years, the continuous development of Internet technology has provided good conditions for the birth and vigorous development of the sharing economy. A number of innovative platform enterprises operating under the mode of sharing economy have emerged in China, which provide convenience for people's food, clothing, housing and transportation consumption. However, the emergence of sharing economy may change the ways of employing of enterprises to a certain extent and may cause a certain degree of impact on the identification of labor relations. Based on the current developmental situation of Chinese sharing economy, this paper classifies the sharing economy into three categories, describes how the three categories of sharing economy affects labor relations, and puts forward the prospect of the development of labor relations under the sharing economy model in China.
\end{abstract}

\section{Keywords}

Sharing Economy, Labor Relation, Internet

\section{Introduction}

In the first 20 years of the 21 st century, the global Internet, mobile communication and mobile device technologies have developed rapidly. People can share and receive a large amount of information through the Internet and enjoy convenient services based on Internet technology. People use mobile devices, based on Internet platforms, third-party payment, big data and other technologies, to integrate a large number of idle resources offline and accurately provide them to the corresponding resource demanders. The supplier temporarily transfers the right to use idle resources, realizes the socialization of production factors, and creates value for the demand side by improving the use efficiency of the stock assets, thereby promoting the sustainable development of the social economy 
[1]. This kind of reuse of idle resources, transforms the sunk cost into economic benefits, improves the efficiency of resource allocation, meets the needs of the interests of both sides of the resource utilization, also contributed to the emergence of the sharing economy.

In recent years, the sharing economy has developed rapidly around the world and has had a certain impact on the current social economy. According to statistics and forecasts from the world's top accounting firm Pricewaterhouse Coopers (PwC), the global sharing economy has reached \$15 billion in 2015. It is expected that by 2025 , the global sharing economy may grow to $\$ 335$ billion. The sharing economy has also developed prosperously in China. In recent years, a number of Internet platform companies based on mobile applications have emerged, such as Xiao Zhu short rental and Ma Yi short rental in the rental industry, Didi Chuxing of the car rental industry, and Ofo and Mobike bicycle sharing platforms which are convenient for the public to travel at close distance. Bicycle sharing platforms were even selected by western media as China's new four major inventions. According to the statistics of the Ministry of Human Resources and Social Security of the People's Republic of China, in 2016, the number of China's laborers employed on the shared economic platform was about 5.85 million. The National Information Center estimates that this number will further increase rapidly, reaching 20 million in 2020.

As a new economic model, the sharing economy involves the sharing and socialization of human capital and physical capital in the regulation, integration and allocation of resources, breaking the fixed contract between the human capital and physical capital. This is different from the current one-to-one traditional economic model that enterprise as the provider of physical capital, the labor as the provider of human capital, and the labor must be attached to the enterprise. This has caused widespread discussion in the society about whether the sharing economy will bring about new labor relations. However, Chinese articles on whether the sharing economy affects labor relations are rare. Some scholars believe that the sharing economic model, compared to the traditional economic model, has changed the status quo of resource regulation and integration, which will further affect the characteristics of human capital. Further, the change in the characteristics of human capital will change the relationship between the human capital owner (labor) and the material resource owner (enterprise), and eventually create a new pattern of labor relations [2]. Other scholars believe that labor relations are generated by the mutual benefit of human capital owners and human capital users. Employers need to use various management methods and regulations to form personal relationships and management relationships with workers to maintain the effective use of human capital. In the sharing economy model, this personal relationship and management relationship still exist. We can't consider that It will form a new personal relationship and management relationship and finally generate a new labor relationship just because the laborer will sell human capital to different employers at the same time [3]. 
Therefore, whether the sharing economy will affect labor relations or even generate new labor relations is still controversial. Changes in national policies, revision of labor laws, and changes in the way that companies regulate the sharing economic platforms will also make variations and uncertainties in the relationship between laborers and platform companies. In view of this problem, this paper combines the current domestic sharing economy status, based on different types of sharing economy, to sort out whether the sharing economy will affect and how to influence labor relations. This paper will firstly introduce the sharing economy; Then, this paper will divide the sharing economy into three categories: Human capital sharing economy, Material capital sharing economy, Both human and material capital sharing economy, and describe the characteristics of these three kinds of sharing economy; Further, this paper will discuss the status of labor relations in the three categories of sharing economies and describe the impact of the three categories of sharing economies on labor relations; Finally, this paper will summarize the current labor relations in the sharing economy and put forward the imagination of the future development of labor relations.

Through the description and discussion of the above content, this article will conceptually contribute to the study of the sharing economy from the perspective of capital types that it proposes a clearer classification of the sharing economy. The current sharing economy research has not yet classified the sharing economy based on the type of capital. This article will also contribute to the academic study of the impact of the sharing economy on labor relations, for the sharing economy is a new type of economy which has developed rapidly in recent years, and many scholars have not yet conducted in-depth research on its impact on the national economy, labor relations, various economic and labor-related laws and policies. This article may also bring some enlightenment to government agents, experts or scholars in the field of labor relations, encourage them to strengthen research on labor relations in the sharing economy model, and introduce more reasonable policies to protect the legitimate rights and interests of labors.

\section{Literature Review}

\subsection{Sharing Economy in the Internet Era}

The word "Sharing Economy" has been proposed for 40 years, and its concept and prototype were proposed by Marcus Felson and Joe L. Spaeth in 1978 [4]. The original form of sharing economy is mainly the sharing of resources or the common consumption between family members or friends, so the sharing economy is also called Collaborative Consumption. It then evolved into a non-profit resource sharing, such as home hosting and recycling of used materials [5]. However, limited by the network technology and communication technology at that time, the sharing economy has not yet developed into an economic model widely accepted by the public. Since 2000, countries around the 
world have gradually become aware of the shortage of resources, and the global appeal for resource protection has gradually strengthened. With the Internet technology effectively connecting online and offline, the sharing economy has become an effective way to save resources [6], and the model of sharing economy has gradually changed from the initial non-profit model to the profit-making model which is support by internet platforms, such as the initial short-rent platform Airbnb and the vehicle rental platform Uber.

The continuous development of Internet technology and mobile device terminal technology is the basis for the sharing economy to become flourish. With the advent of the Internet 2.0 era, the development of information technology has enabled the emergence of online platforms, and has spawned social networks and communication forms, in which "users create content" and "users share content" [7]. Such a social networking platform also connects consumers to people who are interested in sharing idle capital and making a profit. The rise of e-commerce platforms and third-party payments has also reduced consumer search costs and transaction costs. The trust mechanism in the platform also provides credit protection for transactions. Since 2007, the technology of smartphone has developed rapidly, and the penetration rate of mobile devices such as smartphones has increased significantly. As a carrier of the sharing economic platform applications, mobile device terminals such as smartphones provide a hardware foundation for the development of the sharing economy. Based on location service technology (LBS), through mobile telecom operators and wireless networks and GPS positioning, enterprises can easily obtain the location information of mobile device terminal users, which makes peer-to-peer (P2P) services possible, and effectively reduces service costs and efficiency. In addition, big data and cloud computing technology can accurately analyze the consumer's consumption behavior habits, so as to more effectively match the two sides of the transaction.

\subsection{Categories of Sharing Economy}

Different Internet technologies and mobile device terminal technologies have brought different forms of the sharing economy. And because of the essence of the sharing economy is that the supply side will temporarily transfer the right to use the idle physical capital and human capital, from the perspective of the categories of sharing capital, the form of sharing economy can be divided into three categories: human capital sharing economy, material capital sharing economy, and both human and material capital sharing economy.

1) Human capital sharing economy

Human capital sharing economy means that the supplier, as the owner of human capital, only provides the right to use human capital to the shared economic platform enterprises, and does not provide material capital to the platform enterprises. The physical capital required by share the economy is provided by the platform enterprise or the demand side. 
Such platform companies include: Didi Chuxing, Uber, Idachu, Eleme, Hummingbird crowdsourcing, etc. In the case of Didi Chuxing, the drivers of the vehicles owned by platform are the providers of human capital rather than the physical capital providers, because the vehicles used to provide services to the customer belong to the platform. The work content of such drivers is relatively fixed, the driver can not decide whether to provide services for a consumer and can not decide whether to provide services for a certain kind of consumers. All tasks and orders are determined by the Didi Chuxing platform, the driver only need to complete work tasks on time and ensure the quantity.

2) Material capital sharing economy

Material capital sharing economy means that the suppliers have a certain amount of idle material capital and post them to the websites or applications of the sharing economy platform companies. Through the collection, sorting and classification of idle capital information, and through the technologies of big data and cloud computing, platform enterprises can accurately match idle capital to corresponding demanders, and finally complete transactions by means of third-party payment, etc. In this process, the supplier is only responsible for providing idle material capital without providing human capital. The sharing economy of this model truly realizes that "the best use of the material", the demand side can meet the demand with lower cost, and the supply side can benefit from the reuse of resources, which can promote the sustainable development of the social economy.

Such platform companies include Airbnb, Ma Yi short rental, Idelfish, etc. Take Airbnb for example, it is a service-oriented website that connects travelers and homeowners who have idle rooms. It provides website users with a large variety of accommodation information. When the supplier (room owner) has a free room, he can provide the information of the room to the website platform. After the examination, the website platform will include the information, and the demand side (visitors, etc.) will obtain information about the room through certain information search. The demand side can contact the supplier and use the platform to make a short-term booking of the room, generate an order and conclude the transaction.

In addition, there is another kind of material capital sharing economy, that is, the platform enterprise purchase a large amount of material capital (car, bicycle, charging treasure, etc.) and rent the right to use those material capitals to the demand side through the Internet or mobile terminal application, and charge a lower rent from the demand side to achieve a certain degree of profit. Such platform companies include: Ofo bicycle, Mobike bicycle, Like Travel, etc. However, this kind of material capital sharing economy model, because the source of material capital is based on the large investment of platform enterprises, is not the reuse of idle resources. So whether it belongs to the real sharing economy is widely discussed in society.

3) Both human and material capital sharing economy 
Both human and material capital sharing economy means that the supply side not only has idle physical capital, but also provides corresponding human capital. The suppliers provide material capital information and personal information to the corresponding shared economic platform enterprises and become members of the platform through a certain filtering mechanism. The platform enterprises sort and classify information, and based on location service technology (LBS), match the supply side accurately and effectively with the demand side. The demand side will have both the rights to use the material capital and human capital of the supplier at a relatively low price for a certain period of time, and finally achieve an efficient and convenient point-to-point (P2P) service or transaction.

Such platform companies include Didi Chuxing, Uber, DogVacay, etc. Take Didi Chuxing as an example again, different from the drivers of the vehicles owned by platform in the human capital sharing economy, Fast ride car drivers and tailored taxi service drivers in both human and material capital sharing economy usually use their private vehicles (i.e. idle material capital) when serving passengers. They usually have their own personal jobs, and the services on the Didi Chuxing platform usually take up leisure time such as work commuting, holidays, etc., that is, the drivers have their idle human capital. Their service time and service area are flexible, and they can decide whether to provide services at any time.

\section{The Influence of Sharing Economy on Labor Relations}

By describing and exemplifying the characteristics of the three categories of sharing economy in the previous section, it can be roughly understood that different types of sharing economy involve different ways of human capital and physical capital sharing. However, when it comes to the status quo of labor relations in the three sharing economies and whether there are different labor relations in the three sharing economies, we need to firstly understand the identification of labor relations. At the present stage, the identification of Chinese labor relations is based on the subordination. The judgement is mainly based on the academic perspective and legislative basis of the subordination [8].

From the academic perspective of the subordination: It mainly involves two criteria of personality subordination and economy subordination. Personality subordination means that the employing unit has the personalistic and personal control of the labors, and the labors are subject to restrictions on the length of work, the place of work, and the intensity of work from the employing unit [9]. Economy subordination indicates that the work carried out by the labors belongs to the operation content of the employing unit, and the economic activities of the labors are attached to the economic activities of the employing unit.

From the legislative basis of the subordination: To make an identification based on the legislation, we must firstly judge whether the labors have signed the labor contracts with the employing unit. If the two parties have signed the labor 
contract, the labor relation exist. If there is no signing of the labor contract, it is necessary to judge based on the subordination. The Notification on Matters Related to the Establishment of Labor Relations of China (Ministry of Labor and Social Security of the People's Republic of China issued [2005] No. 12) stipulated that if the employing unit recruits the labors without signing a written labor contract, but at the same time satisfies the following circumstances, the labor relation is established. 1) Employing unit and workers are satisfied with the laws and regulations about the qualification of subject; 2) The labor rules and regulations, established by the employing unit, which are in accordance with laws, are applicable to the workers. Laborers are managed by the employing unit's labor management and engaged in work with payment arranged by the employing unit. 3) The labour provided by the labors is an integral part of the employing unit's business.

\subsection{The Status of Labor Relations in Human Capital Sharing Economy and This Sharing Economy's Impact on Labor Relations}

In human capital sharing economy, labors are mainly divided into full-time labors and part-time labors. For example, the drivers of the vehicles owned by platform on Didi Chuxing Platform are usually full-time drivers. Their working hours, clients, and workplaces are limited by Didi Chuxing Platform. They also can't decide when to work, they have a fixed quantity of work each week, and they won't be able to get their percentage from a sum of money if they couldn't complete their jobs. However, there are no labor relations between drivers of the vehicles owned by platform and Didi Chuxing Platform. They need to sign a labor dispatch contract with the labor company in order to work in the form of labor dispatch. A part of takeaway distribution riders of hummingbird crowdsourcing is part-time labors. They have flexible working hours and are free to choose whether to take orders. The same person can work part-time on multiple platforms. However, there is no labor relationship between the distribution riders and the platform. First, the riders did not sign a specific labor contract with the crowdsourcing platform. Secondly, from the perspective of the legislative nature, the three judgment circumstances are not simultaneously achieved.

In combination with the above two situations, some labors have signed labor contracts with labor dispatch companies, and there is a specific labor relationship between labors and labor dispatch companies, while another part of laborers, as part-time workers, have not signed contracts, and there is no specific labor relationship between labors and employing unit. Therefore, the human capital sharing economy generally would not change the existing labor relations at present and has little impact on labor relations. However, in view of the increasing supervision strength of national health and safety of the food industry, it is likely that more policies will be issued in the future, and the takeaway crowdsourcing platforms will be required to strengthen the supervision of the distribution riders. So, this may lead to a different labor relationship other than the 
traditional employment relationship between the platform and the riders.

\subsection{The Status of Labor Relations in Material Capital Sharing Economy and This Sharing Economy's Impact on Labor Relations}

In material capital sharing economy, since the capital suppliers are only responsible for providing idle material capital and do not need to provide human capital to the sharing economic platform enterprises, it does not involve labor. For the material capital suppliers, the platform enterprises are not the employers, so there are no Labor relations between the suppliers and the platforms.

However, the rise of material capital sharing economic platform enterprises has provided more jobs for the society. In particular, platform enterprises which purchase large amounts of material capital (cars, bicycles, charging treasures, etc.) and get profit through rents need to recruit a large number of labors in order to strengthen the management of the operation and maintenance of material capital. For example, Ofo bicycle will recruit bicycle management maintenance workers offline, sign labor contracts with workers, and pay fixed wages to workers, thus forming specific labor relation. Also, for Like Chuxing, this company employs certain internal management, technical, and financial staffs. For the normal use of vehicles, the company will hire maintenance personnel and vehicle management personnel offline. To a certain extent, this type of platform enterprise solves the employment problem of some low-educated labors and provides places for people with employment difficulties caused by the upgrading of industrial structure, which contributes to the stability of labor relations in China. However, it should be noted that due to the chaotic management of personnel in some platform enterprises, the platforms do not provide social insurance for workers. So, some labor disputes may occur.

\subsection{The Status of Labor Relations in Both Human and Material Capital Sharing Economy and This Sharing Economy's Impact on Labor Relations}

In both human and material capital sharing economy, most labors are part-time workers. They have their own jobs and use their leisure time to work on a sharing economic platform. Such as fast ride car drivers and tailored taxi service drivers on Didi Chuxing Platform, their working hours can be decided by themselves. Although the orders are provided by the Didi Chuxing Platform, the drivers can decide whether to take the orders. And for the vehicles, most of the vehicles driven by drivers are private cars, not vehicles provided by the company. Simultaneously, no matter whether it is a part-time or full-time driver, no labor contract will be signed between the platform and the driver. So, fast ride car drivers and tailored taxi service drivers provide both idle human capital and idle material capital by themselves, which is different from the drivers of the vehicles owned by platform.

However, a series of labor disputes have triggered controversy over whether 
there is a labor relationship between the workers and the sharing economic platform enterprises. Some labors believe that work orders come from platform enterprises, and they need to follow the rules and standards set by the platform enterprises. The price of the order is also stipulated by the platform enterprises, and the amount is directly collected by the platforms. The income of labors comes from the amount after deducting a certain income of platforms. Therefore, labors believe that they subject to certain constraints of the platform enterprise. There is part of the personality subordination and certain economy subordination between two sides. So, labor relation exists. But the platform enterprises strictly put forward the explanation based on law: in view of the subject qualification, although the Labor Contract Law, which was enacted in China in 2008, is no longer prohibited for dual labor relations, it is clearly stated that only labors engaged in part-time employment can establish dual labor relations. Most of the workers on the current sharing economic platform have signed full-time employment contracts with other companies, so it doesn't match the subject qualification. In view of labor management, the sharing economy platforms do not directly regulate and control the working hours, workplaces, and work contents of laborers, so there is no labor relation. In view of whether the labor force provided by the workers is part of the platforms' business, the sharing economy platforms believe that they are only responsible for providing information to workers and charging a certain level of fees, so the labor of workers does not belong to the business of the platform. Based on the above factors, the sharing economic platform enterprises believe that there is no labor relationship with the workers.

The different standpoints of the two sides, as well as the ambiguity of the current legislative content in China, pose a difficult problem for the determination of the existence of labor relations. However, in the online car-hailing industry, the state has promulgated management regulations to promote a certain labor relationship between the online car-hailing platforms and the workers. Article 18 of the Interim Measures for the Administration of Online Car-Hailing Operating Services promulgated on July 14, 2016 that the online car-hailing platform companies shall ensure the drivers who provide the service have legal employment qualifications, and in accordance with the relevant laws and regulations, based on the characteristics of working hours and service frequency, sign various forms of labor contracts or agreements with the drivers in order to clarify the rights and obligations of both parties. However, for this interim measure, most platforms will choose to sign labor agreements with the driver, not labor contracts. Therefore, the current labor relations in both human and material capital sharing economy are still unclear and may change. The development of this kind of sharing economy may prompt the state to introduce more policies and laws to regulate labor relations between workers and enterprises, and to protect the personal rights of workers.

\section{Summary and Expectation}

The sharing economy, as burgeoning economic model in recent years, has de- 
veloped rapidly, and has gradually formed three categories of sharing economy, which brought certain influence on China's labor relations. Among the three categories of sharing economy, the human capital sharing economy and the both human and material sharing economy have more impact on labor relations. This is mainly reflected in the difficulty of judging whether there is a labor relationship between the sharing economy platforms and the workers in the new mode of employment. Labors are also difficult to obtain corresponding protection for their rights. So, the rise of these two kinds of sharing economy and the labor dispute cases caused by them will prompt the country to issue various policies and legal documents more quickly to form a better labor relationship or a new type of labor relationship. However, for the material capital sharing economy, because it does not involve human capital, it has less impact on labor relations.

Because the sharing economy is a kind of new economic model that is very different from the traditional economic model, the labor relations in this new economic model will also be greatly different from the traditional labor relations. Using old legal standards of labor relations to evaluate and determine labor relations under the shared economic model will inevitably lead to many problems [10]. Therefore, for the current problems caused by the sharing economy labor relations are uncertain, and the employment of labors transfers from the substantial economy to the sharing economy and breaks away from the labor protection network built by the state and no longer enjoys the labor law to protect the rights of workers [3], considering that China is constantly striving to improve the protection of workers' personal rights and interests, guaranteeing the stability of labor relations, reducing informal labor employment, and broadening access to social security [11]. In the future, the unclear labor relationship between the sharing economy platforms and the workers may obtain a more accurate judicial definition in labor-related laws, and new types of labor relations may be born. Relevant departments may further strengthen the supervision of sharing economic platform enterprises, make the operation of the platform more legal and standardized, improve the status of laborers, and modify the social security system in order to maintain the stability of labor relations.

\section{Limitation and Implications for Future Research}

This study focuses on the emerging sharing economy model in recent years. From the perspective of capital category, the sharing economy is divided into three categories, and it is pointed out that the three types of sharing economy may bring influence or changes to labor relations. However, there are still some limitations in this paper. First, this study only discusses the impact of the sharing economy on labor relations in the Chinese context. Future research could extend the scope of research to more countries and regions. Second, this study has not adopted empirical methods to explore the impact of the sharing economy on labor relations. Future researches could more accurately investigate the impact and the mechanism of impact of the shared economy on labor relations by col- 
lecting macro-economic data of countries or conducting more sharing economic related case studies. In addition, this study analyzes the sharing economy only from the perspective of capital type. Future researches could start with different industries or businesses and explorer the impact of the sharing economy on labor relations based on the perspective of the industry.

\section{Conflicts of Interest}

The author declares no conflicts of interest regarding the publication of this paper.

\section{References}

[1] Zheng, Z.L. (2016) Research on the Causes, Connotation and Business Model of Sharing Economy. Discussion on Modern Economy, 411, 32-36.

[2] Chen, W.B. (2016) The Evolution of Labor Relations Model in the Background of Shared Economy-Based on the Change of Characteristics of Human Capital. Discussion on Modern Economy, No. 9, 35-39.

[3] Wen, X.Y. (2017) Correctly Understand and Grasp the Influence of the Sharing Economy on Labor Relations. Workers Daily, No. 7.

[4] Felson, M. and Spaeth, J. L. (1978) Community Structure and Collaborative Consumption: A Routine Activity Approach. American Behavioral Scientist, 21, 23. https://doi.org/10.1177/000276427802100411

[5] Belk, R. (2014) You Are What You Can Access: Sharing and Collaborative Consumption Online. Journal of Business Research, 67, 1595-1600. https://doi.org/10.1016/j.jbusres.2013.10.001

[6] Botsman, R. and Rogers, R. (2010) What's Mine Is Yours: The Rise of Collaborative Consumption. Harper Business, Doylestown.

[7] Kaplan, A.M. and Haenlein, M. (2010) Users of the World, Unite! The Challenges and Opportunities of Social Media. Business Horizons, 53, 59-68. https://doi.org/10.1016/j.bushor.2009.09.003

[8] Sun, Y. (2017) Research on the Identification of Labor Relations in the Age of China's Sharing Economy. Doctoral Dissertation, Shenzhen University, Shenzhen.

[9] Huang, Y.Q. (2003) New Discussion of Labor Law. China University of Political Science and Law Press, Beijing.

[10] Gan C.H. and Zhou, Z.N. (2017) The Variation, Influence and Regulation of Labor Relations under the Shared Economy Model: A Case Study of Guangzhou Didi Chuxing Company. Trade Union Theory Research: Journal of Shanghai Federation of Trade Unions and Vocational College, No. 6, 19-23+28.

[11] Friedman, E. and Kuruvilla, S. (2015) Experimentation and Decentralization in China's Labor Relations. Human Relations, 68, 181-195. 